\title{
Blockade of NR2B-Containing NMDA Receptors Prevents BDNF Enhancement of Glutamatergic Transmission in Hippocampal Neurons
}

Robert A. Crozier, ${ }^{1}$ Ira B. Black, ${ }^{2}$ and Mark R. Plummer ${ }^{1 ; 3}$

${ }^{1}$ Division of Life Sciences

Rutgers University

Nelson Laboratories

Piscataway, New Jersey 08854-8082 USA

${ }^{2}$ Department of Neuroscience and Cell Biology

Robert Wood Johnson Medical School

University of Medicine and Dentistry of New Jersey

Piscataway, New Jersey 08854 USA

\section{Abstract}

Application of brain-derived neurotrophic factor (BDNF) to hippocampal neurons has profound effects on glutamatergic synaptic transmission. Both pre- and postsynaptic actions have been identified that depend on the age and type of preparation. To understand the nature of this diversity, we have begun to examine the mechanisms of BDNF action in cultured dissociated embryonic hippocampal neurons. Whole-cell patch-clamp recording during iontophoretic application of glutamate revealed that BDNF doubled the amplitude of induced inward current. Coexposure to BDNF and the NMDA receptor antagonist AP-5 markedly reduced, but did not entirely prevent, the increase in current. Coexposure to BDNF and ifenprodil, an NR2B subunit antagonist, reproduced the response observed with AP-5, suggesting BDNF primarily enhanced activity of NR2B-containing NMDA receptors with a lesser effect on non-NMDA receptors. Protein kinase involvement was confirmed with the broad spectrum inhibitor staurosporine, which prevented the response to BDNF. PKCI19-31 and H-89, selective antagonists of PKC and PKA, had

${ }^{3}$ Corresponding author. no effect on the response to BDNF, whereas autocamtide-2-related inhibitory peptide, an antagonist of CaM kinase II, reduced response magnitude by $60 \%$. These results demonstrate the predominant role of a specific NMDA receptor subtype in BDNF modulation of hippocampal synaptic transmission.

\section{Introduction}

It is now well established that brain-derived neurotrophic factor (BDNF) and other neurotrophins (NTs) are capable of rapidly enhancing synaptic transmission in a variety of experimental preparations, both in vivo and in vitro (for review, see McAllister et al. 1999). Effects range from enhancement or inhibition of baseline transmission in hippocampal slices (Kang and Schuman 1995, 1996; Tanaka et al. 1997) and in cell culture (Levine et al. 1995, 1996, 1998; Wang and Poo 1997) to alterations in the threshold for producing long-term potentiation (LTP) (Figurov et al. 1996; Korte et al. 1996; Patterson et al. 1996; Akaneya et al. 1997; Kang et al. 1997; Gottschalk et al. 1998) and longterm depression (LTD) (Akaneya et al. 1996; Huber et al. 1998; Kinoshita et al. 1999). Both pre- and postsynaptic mechanisms have been proposed to account for these observations, indicative of the complex nature of NT modulation of synaptic transmission.

The diversity of NT action reflects factors such as age and activity dependence. For example,

LEARNING \& MEMORY 6:257-266 @ 1999 by Cold Spring Harbor Laboratory Press ISSN1072-0502/99 \$5.00

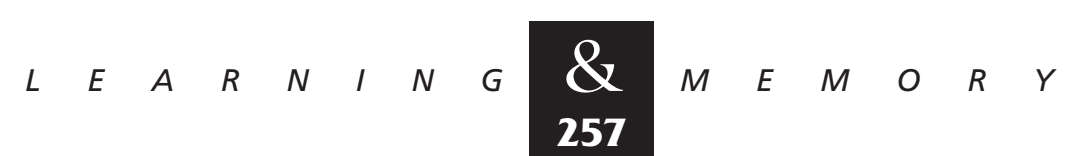


BDNF has been shown to promote induction of LTP in early postnatal, but not adult rats (Figurov et al. 1996). BDNF has also been shown to have distinct effects depending on activity levels (Rutherford et al. 1997, 1998; Gottschalk et al. 1998; Turrigiano et al. 1998), and the pattern of stimuli used to induce LTP (Kang et al. 1997; Korte et al. 1998).

At present, the molecular mechanisms that mediate these diverse NT effects are unknown. NT binding to the cognate trk receptors activates manifold intracellular signaling cascades that have both local and nuclear actions (for review, see Segal and Greenberg 1996). To simplify analysis of the relevant pathways, we initially focused on effectors known to modulate synaptic transmission. Both specific neurotransmitter receptors and presynaptic proteins have been implicated in BDNF's effects on synaptic efficacy.

To begin to elucidate one mechanism of BDNF action, we have focused on trkB modulation of NMDA receptor activity in cultured embryonic hippocampal neurons. We and others found previously that exposure to BDNF results in NMDA receptor phosphorylation (Suen et al. 1997, 1998; Lin et al. 1998), and enhancement of NMDA receptor activity (Levine et al. 1998; Song et al. 1998). BDNF specifically and selectively increases phosphorylation of the NR2B and NR1 subunits of the NMDA receptor. Enhanced phosphorylation of NR2B is particularly provocative as this post-translational modification is also associated with LTP (Rosenblum et al. 1996; Rostas et al. 1996). In the present study, we examine this issue in a physiological context by using subtype-specific glutamate receptor antagonists. In particular, we find equivalent inhibitory effects of AP-5 and ifenprodil, suggesting that the action of BDNF is largely mediated via NR2B-containing NMDA receptors. We show further that $\mathrm{Ca}^{2+} /$ calmodulin kinase II (CaMKII) is an important element of the transduction pathway.

\section{Material and Methods}

\section{CELL CULTURE}

Hippocampal cultures were grown as described previously (Levine et al. 1995). Briefly, hippocampi were obtained from embryonic day 18 Sprague-Dawley rats and placed into cold PBS. Cells were triturated in $2 \mathrm{ml}$ of Eagle's minimum essential medium (MEM) with added glucose and $7.5 \%$ FBS and plated on poly-D-lysine-coated petri dishes at a final density of $10^{6}$ cells/35-mm dish. Cultures were maintained in serum-free medium (SFM) at $37^{\circ} \mathrm{C}$ in a $95 \%$ air $/ 5 \% \mathrm{CO}_{2}$ humidified incubator. SFM consisted of a 1:1 ( $\mathrm{vol} / \mathrm{vol})$ mixture of Ham's F-12 and MEM and supplemented with 25 $\mu \mathrm{g} / \mathrm{ml}$ insulin, $100 \mu \mathrm{g} / \mathrm{ml}$ transferrin, $60 \mu \mathrm{M}$ putrescine, $20 \mathrm{~nm}$ progesterone, $30 \mathrm{~nm}$ selenium, $6 \mathrm{mg} /$ $\mathrm{ml}$ glucose, and $0.5 \mathrm{U} / \mathrm{ml}$ and $0.5 \mathrm{mg} / \mathrm{ml}$, respectively, penicillin-streptomycin.

\section{RECORDINGS AND EXPERIMENTAL TREATMENTS}

Voltage clamp recordings were obtained from pyramidal-type cells after 12-16 days in vitro by standard techniques (Hamill et al. 1981). Cells were recorded in voltage clamp mode and held at a resting potential of $-40 \mathrm{mV}$ to reduce $\mathrm{Mg}^{2+}$ blockade of NMDA receptors. The external bath solution contained $1.67 \mathrm{~mm} \mathrm{Ca}, 1 \mathrm{~mm} \mathrm{Mg}, 5.36 \mathrm{~mm}$ $\mathrm{K}, 137 \mathrm{~mm} \mathrm{Na}, 17 \mathrm{~mm}$ glucose, $10 \mathrm{~mm}$ HEPES, 0.001 mM TTX, and $20 \mathrm{~mm}$ sucrose. The pipette solution contained $105 \mathrm{~mm}$ Cs methanesulfonate, $15 \mathrm{~mm}$ Cs-Cl, $10 \mathrm{~mm}$ HEPES-CsOH, $0.2 \mathrm{~mm}$ EGTA, $8 \mathrm{~mm}$ $\mathrm{NaCl}, 2 \mathrm{~mm}$ Mg-ATP, $2 \mathrm{~mm} \mathrm{Na}-\mathrm{ATP}, 0.3 \mathrm{~mm} \mathrm{Na-}$ GTP, $20 \mathrm{~mm}$ phosphocreatinine, and $50 \mathrm{U} / \mathrm{ml}$ creatinine phosphokinase. The $\mathrm{pH}$ of the internal solution was set to 7.3 with $\mathrm{CsOH}$. Signals were recorded with an Axopatch 200 amplifier (Axon Instruments), sampled at $2.5 \mathrm{kHz}$ (INDEC IDA15125 interface) and filtered at $5 \mathrm{kHz}$. Threebarrel micropipettes were used for iontophoretic application of drugs. One barrel, filled with $0.1 \mathrm{M}$ $\mathrm{NaCl}$, was used for current balancing. Other barrels were filled with either L-glutamate (0.2 $\mathrm{m}$ at $\mathrm{pH} 7.5)$ or saline control. Iontophoretic pulses were applied at 10-sec intervals with an ejection time sufficient to achieve stable and consistent responses (typically 2-10 msec). Ejection current was adjusted to elicit a peak glutamate current of 30-50 pA. BDNF (Peprotech) was prepared as a stock in PBS with $1 \mu \mathrm{g} / \mathrm{ml}$ bovine serum albumin, diluted 500-fold into bath solution, and was applied via a microperfusion system (Ogata and Tatebayashi 1991) at a final concentration of $20 \mathrm{ng} / \mathrm{ml}$. All drugs except AP-5 were prepared as $1000 \times$ stock solutions and diluted into either the bath or pipette solution or both. AP-5 was prepared as a $500 \times$ stock solution. Final concentrations of $1 \mu \mathrm{M}$ staurosporine, $1 \mu \mathrm{M} \mathrm{H}-89$, and $3 \mu \mathrm{M}$ ifenprodil were dissolved in ethanol. PKCI 19-31 (3-50 $\mu \mathrm{M})$ was dissolved in 5\% AcOH. Autocamtide-2-related inhibitory peptide (AIP) (myristoylated, $1 \mu \mathrm{M}$ ) and all other drugs were dissolved in water. When tested,

$$
\begin{array}{llllllllllllllll} 
& E & A & R & N & I & N & G & \boldsymbol{\bigotimes} \\
\mathbf{2 5 8} & M & E & M & O & R & Y
\end{array}
$$


all protein kinase inhibitors were included in the recording pipette. Experiments with staurosporine and H-89 also included a $1-\mathrm{hr}$ preincubation period to allow time for the membrane-permeable compound to enter the cell. They were also included in the bath solution. Glutamate receptor antagonists were included in the bath solution as indicated in the figures. AP-5 and TTX were purchased from RBI (Natick, MA). All other drugs were purchased from Calbiochem (La Jolla, CA).

\section{DATA ANALYSIS}

Data were analyzed by measuring the peak current amplitude for each iontophoretic pulse during the baseline and test periods. Experiments were kept for analysis if they showed $< \pm 10 \%$ change during the $5 \mathrm{~min}$ of baseline recording prior to addition of BDNF. Student's $t$-test was used for statistical comparisons (two-tailed with $P<0.05$ indicating significance).

\section{Results}

As we have shown previously shown (Levine et al. 1998), the amplitude of glutamate-induced currents is increased by exposure to BDNF (Fig. 1). Iontophoretic application of glutamate to the base of dendritic processes in cultured embryonic hippocampal neurons evoked a transient inward current with a reversal potential of $\sim 0 \mathrm{mV}$. At the beginning of a recording, the injection parameters were adjusted to elicit a current with a peak amplitude of 30-50 pA. Although we occasionally observed hot spots (Trussell et al. 1988; Jones and Baughman 1991), they were not encountered with sufficient frequency to allow systematic study. We therefore limited our analysis to the relatively slow responses produced by activation of numerous synaptic sites, presumably including both synaptic and extrasynaptic neurotransmitter receptors.

After establishing stable baseline measurements, BDNF was bath applied while continuing to elicit currents with glutamate iontophoresis. A small increase in the current was observed within 1 min after exposure to BDNF, but the current continued to rise with the period of largest increase beginning at $\sim 7$ min (Fig. 1B). BDNF elicited an approximate doubling in current amplitude $(182 \pm 10 \%, n=9)$ with a mean latency to halfmaximal response of $15.4 \pm 0.8 \mathrm{~min}$.
A

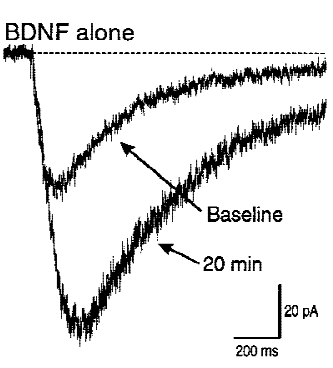

C

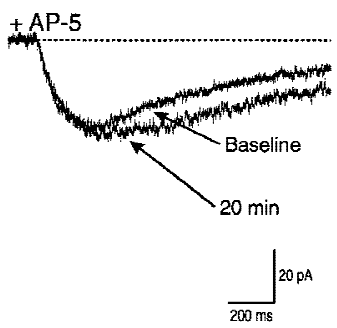

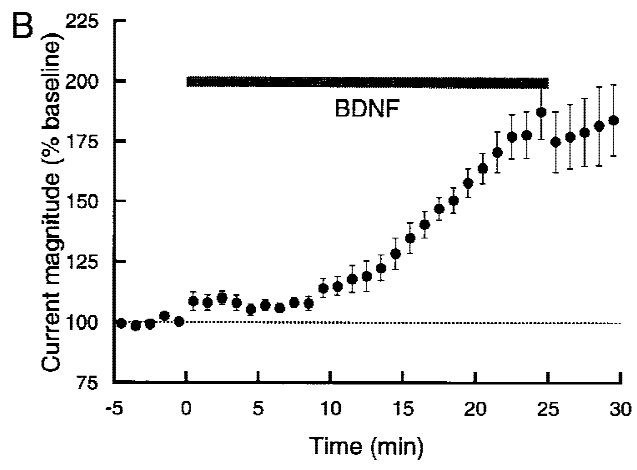

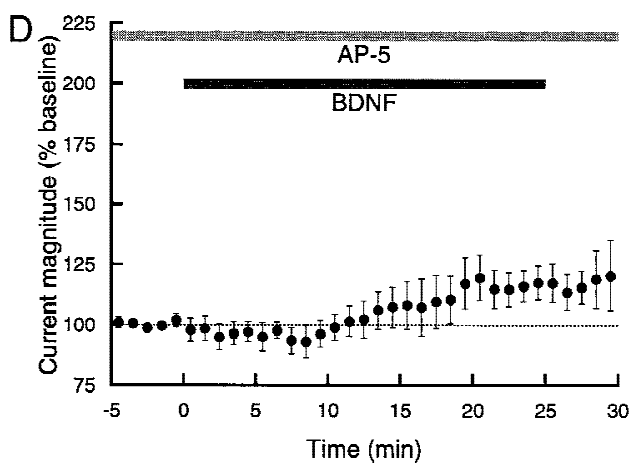

Figure 1: BDNF enhancement of glutamate-induced current is strongly attenuated in the presence of AP-5. (A) Example traces showing the current prior to, and 20 min after, exposure to BDNF. Under control conditions, the peak amplitude of the current doubled. In this and all subsequent figures, the traces shown are an average of three individual currents. $(B)$ Average time course of the response to BDNF $(n=9)$. Peak current amplitude was normalized to baseline. Note that in this and subsequent figures the $y$-axis starts at $75 \%$ with $100 \%$ indicating no response to BDNF. (Top) Bar shows when BDNF was applied. There was an early small increase in the current followed by a substantially greater response that starts at $\sim 7 \mathrm{~min}$. (C) Example traces showing the effect of BDNF during bath application of $50 \mu \mathrm{M}$ AP-5. The current showed a modest increase at $20 \mathrm{~min}$. (D) Average time course of the response to BDNF in AP-5 $(n=4)$. (Top) Bars show when BDNF and AP-5 were applied. Although the response was much smaller, it proceeded along at the same general rate as under control conditions.

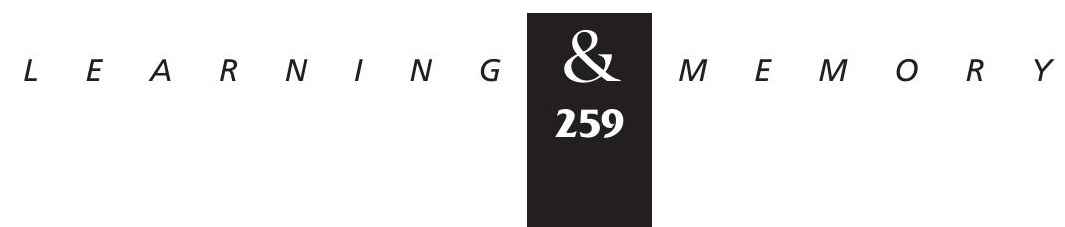




\section{Crozier et al.}

Our earlier work with selective agonists (Levine et al. 1998) indicated that the effect of BDNF was predominantly on NMDA receptor current. To confirm this result, we examined the effect of AP-5, a selective NMDA receptor antagonist (Davies et al. 1981). In the presence of AP-5, the glutamate-induced current exhibited only a small increase following exposure to BDNF (Fig. 1C,D). Twenty minutes after exposure, the magnitude of the current was increased by $<20 \%(117 \pm 7.4 \%$ increase over baseline, $n=4)$. Although it attained a much smaller magnitude, the current did increase with a time course that was similar to that seen when only BDNF was applied. The mean latency to half-maximal amplitude was $16.5 \pm 3.3$ min, which was not significantly different from that seen with BDNF alone $(P>0.6)$.

In parallel biochemical studies, we have shown that exposure to BDNF results in rapid phosphorylation of the NR2B subunit of the NMDA receptor (Lin et al. 1998). To begin defining subtype specificity, we examined the effects of ifenprodil, a selective antagonist of NMDA receptors that contain NR2B (Williams 1993). Ifenprodil substantially reduced the action of BDNF, reproducing the effect of AP-5 (Fig. 2). Comparison of individual traces prior to BDNF application with those $20 \mathrm{~min}$ after BDNF application showed that the current increased by $<20 \%$ ( $117 \pm 7.2 \%$ of baseline, $n=4)$. Once again, the time course of the response was generally similar to that seen with BDNF alone or $\mathrm{BDNF}+\mathrm{AP}-5$. The mean latency to half-maximal response was $14.2 \pm 4.5 \mathrm{~min}$. This value was not significantly different from either BDNF alone $(P>0.6)$ or $\mathrm{BDNF}+\mathrm{AP}-5(P>0.6)$.

Of the possible mechanisms that could account for the increase in current seen after bath perfusion of BDNF, two are most probable. First, the combination of BDNF exposure and calcium influx through NMDA receptors may have led to increased responsiveness of AMPA/kainate receptors. Second, BDNF either directly, or indirectly via calcium influx, may have enhanced activity of NMDA receptors. To distinguish between these two hypotheses, we bath applied AP-5 after 25 min of exposure to BDNF (Fig. 2C,D). The NMDA receptor antagonist largely eliminated the BDNF-increased glutamate current, decreasing it to $106 \pm 8.9 \%$ of baseline level $(n=5)$ a value significantly different from BDNF alone $(P<0.001)$. The current that remained, however, was not significantly different from the small increase in glutamate current seen with coexposure of BDNF and AP-5 $(P>0.4)$ or ifenprodil $(P>0.4)$. These data
Figure 2: The effect of BDNF on glutamate-activated current can be reduced by an NR2B antagonist. (A) Superimposed example traces showing currents during the baseline period and after 20 min exposure to BDNF. Ifenprodil ( $3 \mu \mathrm{M})$ was present in the bath throughout the recording. BDNF elicited a modest increase in current. $(B)$ Time course of the response to BDNF in the presence of ifenprodil $(n=4)$. The increase in the current was indistinguishable from that seen when AP-5 was used (cf. with Fig. 1D). (C) Superimposed example traces showing the block produced by AP-5 on the component of current increased by BDNF. (D) Time course of the response to BDNF followed by application of AP-5 at 25 min into the recording. Note that AP-5 almost entirely blocked the current that had been increased by BDNF.
A

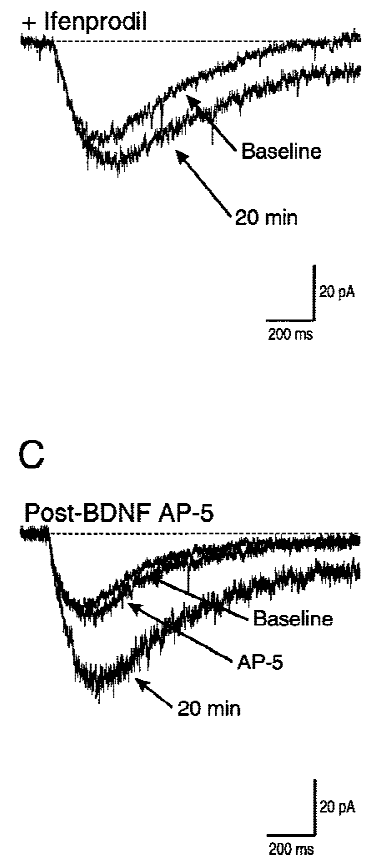

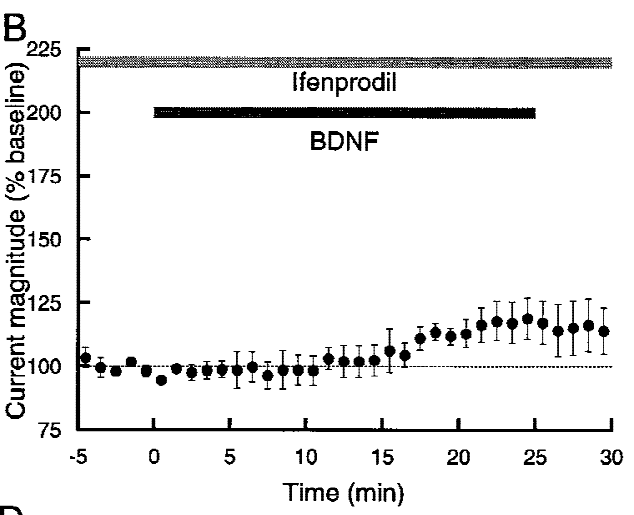

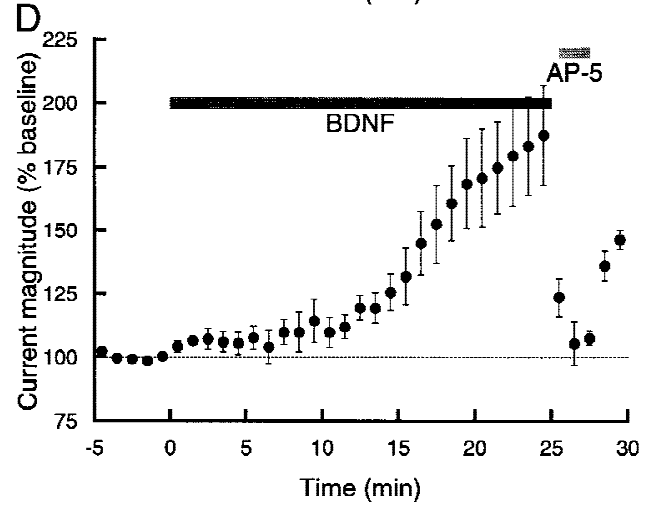

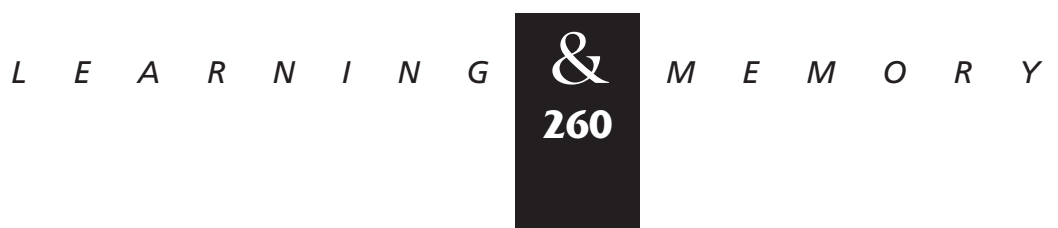


A

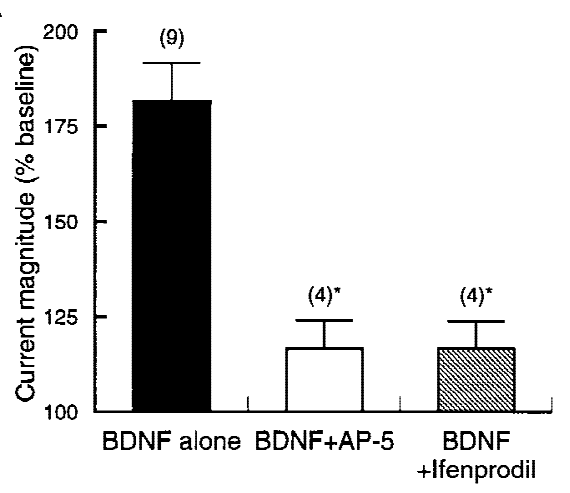

B

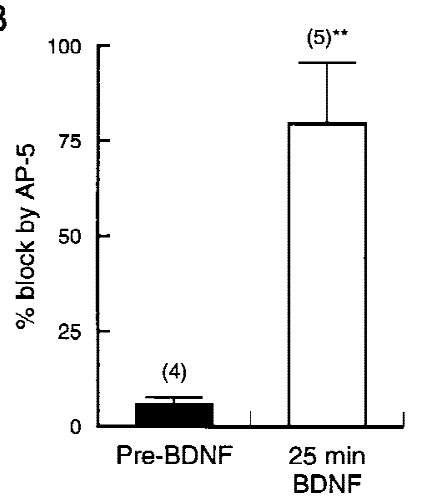

Figure 3: Comparison of glutamate receptor antagonists shows NR2B dependence of BDNF effect. (A) Magnitude of glutamate-activated current after 20-25 min of exposure to BDNF. AP-5 and ifenprodil reduced the response to similar levels. $\left.{ }^{*}\right) P<0.005$ vs. BDNF alone. $(B)$ Percent block of the glutamate-activated current either prior to, or 25 min following application of BDNF. The far greater block by AP-5 after exposure to BDNF further demonstrates that it is NMDA receptor activity that is upregulated by BDNF. (**) $P<0.001$ vs. Pre-BDNF. effectively rule out the first mechanism and support increased NMDA receptor activity as the explanation for the effect of BDNF.

Comparison of the effects of NMDA receptor antagonists (Fig. 3) highlights several points. First, BDNF primarily activates a population of NMDA receptors that contain the NR2B subunit. This is suggested by the virtually identical effect produced by the nonspecific NMDA receptor antagonist AP-5 and the subtype-selective antagonist ifenprodil. Second, the NMDA receptors recruited by BDNF are almost silent prior to trkB activation (Fig. 3B). Almost $80 \%(79.8 \pm 16 \%, n=5)$ of the glutamate current increased by BDNF was blocked by subsequent application of AP-5. This is in contrast to the reduction produced by AP- 5 prior to BDNF exposure, which was only $5.9 \pm 1.7 \%$ of baseline $(n=5$; traces not shown). Further confirmation of the lack of NMDA receptor involvement in the baseline current was obtained with CNQX, which almost entirely blocked the current seen prior to BDNF application (data not shown).

Having demonstrated the involvement of
NR2B-containing NMDA receptors in the effect of BDNF, we began examining intracellular signals that potentially transduce trkB activation into NMDA receptor stimulation. In previous studies, the requirement for trkB activation was shown with the trk kinase inhibitor K252a (Levine et al. 1995, 1998). Therefore, we examined phosphorylation dependence of the current enhancement with a broad spectrum protein kinase inhibitor, staurosporine. Bath application of staurosporine prior to addition of BDNF completely eliminated the increase in current without having any apparent effect on the baseline response to glutamate iontophoresis (Fig. 4A). After $25 \mathrm{~min}$ of exposure to BDNF, the glutamate-activated current was essentially unchanged $(98.8 \pm 5.3 \%$ of baseline, $n=4)$. At no time during the entire course of BDNF exposure was there any apparent effect on the amplitude of the current (Fig. 4B).

The relatively nonselective nature of staurosporine inhibition precluded any conclusions about specific protein kinases involved in BDNF enhancement of synaptic transmission. To gain
A

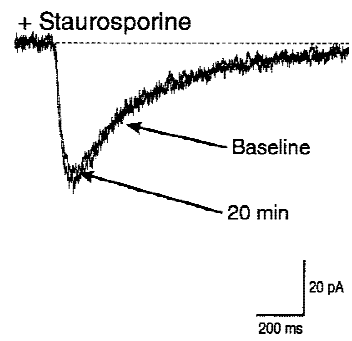

\section{B}

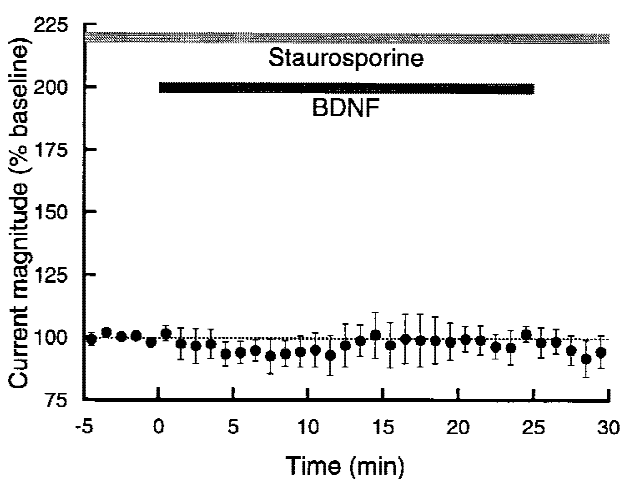

Figure 4: Enhancement of glutamateinduced current is prevented by bath application of staurosporine. (A) Superimposed example traces showing the response to glutamate iontophoresis prior to, and 20 min after, application of BDNF in the presence of $1 \mu \mathrm{M}$ staurosporine. The two traces are essentially indistinguishable. (B) Time course showing that bath application of staurosporine completely prevented the increase in the glutamate-activated current normally seen following exposure to BDNF $(n=4)$.

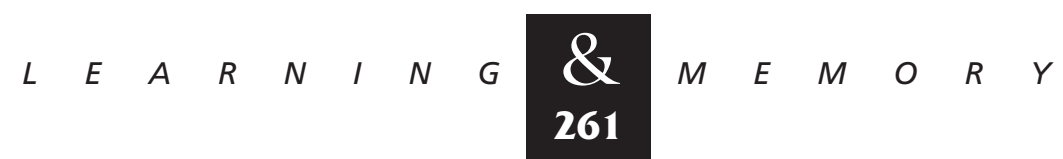




\section{Crozier et al.}

some insight into this question, we examined the effects of three additional inhibitors; PKCI19-31, H-89, and AIP, relatively specific inhibitors of protein kinase C (PKC), cyclic-AMP-dependent protein kinase (PKA) and CaMKII, respectively (Fig. 5). Somewhat surprisingly, given the known effects of PKA and PKC on AMPA and NMDA receptors (for review, see Moss and Smart 1996), neither H-89 nor PKCI19-31 had any effect on the BDNF-induced increase in glutamate current. Preliminary experiments with two other PKC inhibitors (Gö 7874 and calphostin C) were also without effect (data not shown). AIP, however, substantially reduced the response to BDNF. In the presence of the CaMKII inhibitor, the current increased by only $132 \pm 6.3 \%(n=3)$, significantly less than that with BDNF alone $(P<0.05)$. As with AP-5 and ifenprodil, the block of the BDNF effect was not complete; the increase in current was significantly greater than that seen with staurosporine $(P<0.05)$. Thus, although AIP may have eliminated the increase in the NMDA component of current, it did not entirely prevent the action of BDNF.

\section{Discussion}

In this study we have examined the mechanisms by which BDNF rapidly augments hippocampal synaptic transmission using selective antagonists of glutamatergic transmission and inhibitors of protein kinases. Our results indicate that enhanced activity of NMDA receptors, specifically those that contain the NR2B subunit, is the predominant postsynaptic consequence of trkB activation. Prior to BDNF application, iontophoretic application of glutamate elicited a substantially AP-5insensitive current carried by AMPA receptors.
Exposure to BDNF resulted in a doubling of glutamate-activated current, but the pharmacology of this additional component of current differed from the baseline current in its sensitivity to AP-5 and ifenprodil. Bath application of AP-5 during BDNF exposure largely prevented the increase in glutamate current; exposure to AP-5 after BDNF had increased the current returned the response to virtually baseline levels, and application of ifenprodil reproduced the action of AP-5. The near identity of the response time courses (cf. Figs. 1D and 2B) suggests that NMDA receptors on the hippocampal cells from which we recorded were almost entirely of the NR2B-containing subtype. It is important to point out, however, that the NMDA receptor antagonists we used did not block the BDNF response completely, thus leaving open the possibility of relatively small effects on non-NMDA receptors.

These physiological studies are entirely consistent with our characterization of the actions of BDNF on NMDA receptors in synaptoneurosomes or isolated postsynaptic densities (PSDs) (Suen et al. 1997, 1998; Lin et al. 1998). Incubation of a high-affinity concentration $(2 \mathrm{ng} / \mathrm{ml})$ of BDNF with hippocampal or cortical PSDs for $5 \mathrm{~min}$ elicits maximal phosphorylation to levels associated with LTP (Lin et al. 1998). This action is specific and selective, because tyrosine phosphorylation of NR2A is unaffected, and because nerve growth factor (NGF) another NT, is ineffective. We tentatively conclude that tyrosine phosphorylation of NR2Bcontaining NMDA receptors is associated with a postsynaptic locus of enhanced synaptic transmission elicited by BDNF.

Other studies of NT modulation of hippocampal synaptic transmission have not found an enhancement of NMDA receptor activity (Kang and

Figure 5: Comparison of the actions of PKC, PKA, and Ca/CAM kinase antagonists. Magnitude of glutamate-activated current after 20-25 min exposure to BDNF either alone (same data as in Fig. 3 ), in vehicle solution, or in the presence of different protein kinase inhibitors. The nonspecific inhibitor staurosporine completely prevented current enhancement by BDNF, (**) $P<0.001$ vs. BDNF alone, whereas inhibitors of PKA and PKC were without effect. The CaMKII inhibitor, however, substantially, but not fully,

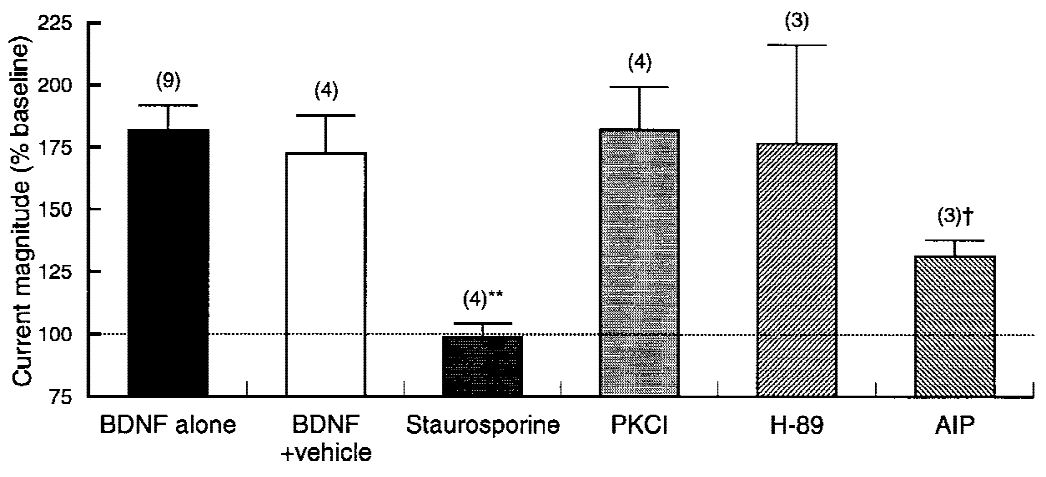
blocked the action of BDNF. $\left({ }^{+} P<0.05\right.$ vs. BDNF alone and $P<0.05$ vs. staurosporine. Note that the $y$-axis starts at $75 \%$, with $100 \%$ indicating no response (horizontal broken line). Numbers in parentheses indicate number of recordings.

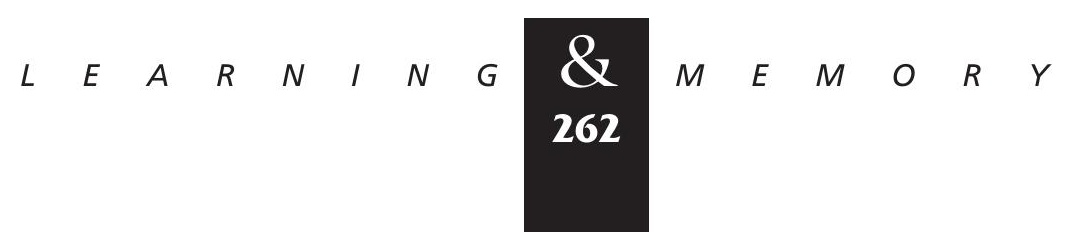


Schuman 1995; Figurov et al. 1996; Frerking et al. 1998). The results reported here may offer a straightforward explanation. We have studied neurons obtained from E18 rats that were maintained in culture for 2 weeks. Eighty percent of the glutamate current increased by BDNF is blocked by ifenprodil, suggesting that the effect is almost entirely on NR2B-containing NMDA receptors. It has been shown that NR2B levels decrease with age (Kirson and Yaari 1996; Li et al. 1998; Stocca and Vicini 1998), whereas NR2A levels increase with age (Monyer et al. 1994). If BDNF modulation of NMDA receptors is age- and channel-subtype specific, then it may be difficult to detect in hippocampal slice preparations obtained from older animals. In support of this, our previous work indicates that BDNF specifically induces phosphorylation of NR2B, but not NR2A, in isolated PSDs (Lin et al. 1998).

By using relatively selective protein kinase antagonists, we have also gained some insight into mechanisms that mediate trkB enhancement of NMDA receptor activity. Neither PKA nor PKC appear to be important members of the transduction pathway; however, CaMKII does. In the presence of AIP, the response to BDNF was substantially reduced. This correlates well with the high levels of CaMKII found in the PSD (Yoshimura et al. 1996; Strack et al. 1997; Yoshimura and Yamauchi 1997; Gardoni et al. 1998), but the lack of complete inhibition by AIP leaves open the possibility that other kinases are involved. The current that remains during coexposure to ifenprodil, AP-5 and AIP, may result from a common mechanism involving non-NMDA glutamate receptors and working through a separate mechanism.

These studies suggest the intriguing possibility that upregulation of the NMDA receptor depends on its own activity. Bath application of AP-5 and ifenprodil prevented the BDNF-induced increase in current, which would not only block manifestation of the response, but may also interfere with its induction. Our experiments do not distinguish between a model in which calcium entry through the NMDA receptor is required for the trkB-mediated response or an activity-independent model in which the response depends exclusively on cytoplasmic second-messenger cascades.

It has been proposed that NTs are required for activity-dependent modification of synaptic connectivity during development (Domenici et al. 1991; for review, see Katz and Shatz 1996). BDNFinduced increases in dendritic arborization are pre- vented by suppression of neuronal activity (McAllister et al. 1996); formation of ocular dominance columns is disrupted when BDNF is added in excess (Cabelli et al. 1995) or is removed with trk-BIgG (Cabelli et al. 1997), and effects of monocular deprivation can be reversed by BDNF administration (Galuske et al. 1996). Related studies suggest that LTP (Kirkwood et al. 1995), and consequently NMDA receptors (Bear and Colman 1990; Bear et al. 1990), may be critical for this type of synaptic modification. Our results, which bring together characteristic actions of BDNF on NMDA receptors in embryonic hippocampus, are entirely consistent with the view that NT modulation of glutamatergic synaptic transmission is essential to normal synaptic maturation. Further support for this idea comes from a recent study of synaptic and extrasynaptic glutamate receptors in which NR1/ NR2B diheteromeric receptors were hypothesized to mark synapses available for further elaboration (Tovar and Westbrook 1999).

Neurotrophins have a pervasive role in the plasticity of the developing and adult nervous system. TrkB ligands, in particular, have been shown to influence synaptic transmission in cortical, subcortical, sensory, and motor systems via both preand postsynaptic mechanisms. The anterograde transport (Tongiorgi et al. 1997; Altar and DiStefano 1998) and regulated release (Goodman et al. 1996; Mowla et al. 1999) of BDNF further supports its central role in activity-dependent modification of synaptic efficacy.

\section{Acknowledgments}

We are grateful to Dr. R. L. Davis for helpful discussions and comments on the manuscript. Supported by the National Institutes of Health (NS 34061 and HD 23315).

The publication costs of this article were defrayed in part by payment of page charges. This article must therefore be hereby marked "advertisement" in accordance with 18 USC section 1734 solely to indicate this fact.

\section{References}

Akaneya, Y., T. Tsumoto, and H. Hatanaka. 1996. Brain-derived neurotrophic factor blocks long-term depression in rat visual cortex. J. Neurophysiol. 76: 4198-4201.

Akaneya, Y., T. Tsumoto, S. Kinoshita, and H. Hatanaka. 1997. Brain-derived neurotrophic factor enhances long-term potentiation in rat visual cortex. J. Neurosci. 17: 6707-6716.

Altar, A. and P.S. DiStefano. 1998. Neurotrophin trafficking by anterograde transport. Trends Neurosci. 21: 433-437.

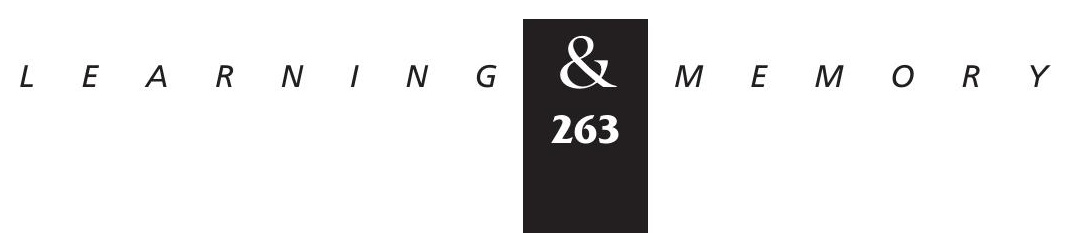




\section{Crozier et al.}

Bear, M.F. and H. Colman. 1990. Binocular competition in the control of geniculate cell size depends upon visual cortical N-methyl-D-aspartate receptor activation. Proc. Natl. Acad. Sci. 87: 9246-9249.

Bear, M.F., A. Kleinschmidt, Q.A. Gu, and W. Singer. 1990. Disruption of experience-dependent synaptic modifications in striate cortex by infusion of an NMDA receptor antagonist. J. Neurosci. 10: 909-925.

Cabelli, R.J., A. Hohn, and C.J. Shatz. 1995. Inhibition of ocular dominance column formation by infusion of NT-4/5 or BDNF. Science 267: 1662-1666.

Cabelli, R.J., D.L. Shelton, R.A. Segal, and C.J. Shatz. 1997. Blockade of endogenous ligands of TrkB inhibits formation of ocular dominance columns. Neuron 19: 63-76.

Davies, J., A.A. Francis, A.W. Jones, and J.C. Watkins. 1981. 2-Amino-5-phosphonovalerate 2APV), a potent and selective antagonist of amino acid-induced and synaptic excitation. Neurosci. Lett. 21: 77-81.

Domenici, L., Berardi, N., Carmignoto, G., Vantini, G., and Maffei, L. 1991. Nerve growth factor prevents the amblyopic effects of monocular deprivation. Proc. Natl. Acad. Sci. 88: $8811-8815$.

Figurov, A., L.D. Pozzo-Miller, P. Olafsson, T. Wang, and B. Lu. 1996. Regulation of synaptic responses to high-frequency stimulation and LTP by neurotrophins in the hippocampus. Nature 381: 706-709.

Frerking, M., R.C. Malenka, and R.A. Nicoll. 1998. Brain-derived neurotrophic factor (BDNF) modulates inhibitory, but not excitatory, transmission in the CA1 region of the hippocampus. J. Neurophysiol. 80: 3383-3386.

Galuske, R.A., D.S. Kim, E. Castren, H. Thoenen, and W. Singer. 1996. Brain-derived neurotrophic factor reversed experience-dependent synaptic modifications in kitten visual cortex. Eur. J. Neurosci. 8: 1554-1559.

Gardoni, F., A. Caputi, M. Cimino, L. Pastorino, F. Cattabeni, and M. Di Luca. 1998. Calcium/calmodulin-dependent protein kinase II is associated with NR2A/B subunits of NMDA receptor in postsynaptic densities. J. Neurochem. 71: 1733-1741.

Goodman, L.J., J. Valverde, F. Lim, M.D. Geschwind, H.J. Federoff, A.I. Geller, and F. Hefti. 1996. Regulated release and polarized localization of brain-derived neurotrophic factor in hippocampal neurons. Mol. Cell. Neurosci. 7: 222-238.

Gottschalk, W., L.D. Pozzo-Miller, A. Figurov, and B. Lu. 1998. Presynaptic modulation of synaptic transmission and plasticity by brain-derived neurotrophic factor in the developing hippocampus. J. Neurosci. 18: 6830-6839.

Hamill, O.P., A. Marty, E. Neher, B. Sakmann, and F.J. Sigworth. 1981. Improved patch-clamp techniques for high-resolution current recording from cells and cell-free membrane patches. Pfluegers Arch. 391: 85-100.

Huber, K.M., N.B. Sawtell, and M.F. Bear. 1998. Brain-derived neurotrophic factor alters the synaptic modification threshold in visual cortex. Neuropharmacology 37: $571-579$.

Jones, K.A. and R.W. Baughman. 1991. Both NMDA and non-NMDA subtypes of glutamate receptors are concentrated at synapses on cerebral cortical neurons in culture. Neuron 7: 593-603.

Kang, H. and E.M. Schuman. 1995. Long-lasting neurotrophin-induced enhancement of synaptic transmission in the adult hippocampus. Science 267: 1658-1662.

1996. A requirement for local protein synthesis in neurotrophin-induced hippocampal synaptic plasticity. Science 273: 1402-1406.

Kang, H., A.A. Welcher, D. Shelton, and E.M. Schuman. 1997. Neurotrophins and time: Different roles for TrkB signaling in hippocampal long-term potentiation. Neuron 19: $653-664$.

Katz, L.C. and C.J. Shatz. 1996. Synaptic activity and the construction of cortical circuits. Science 274: 1133-1138.

Kinoshita, S., H. Yasuda, N. Taniguchi, R. Katoh-Semba, H. Hatanaka, and T. Tsumoto. 1999. Brain-derived neurotrophic factor prevents low-frequency inputs from inducing long-term depression in the developing visual cortex. J. Neurosci. 19: $2122-2130$.

Kirkwood, A., H.K. Lee, and M.F. Bear. 1995. Co-regulation of long-term potentiation and experience-dependent synaptic plasticity in visual cortex by age and experience. Nature 375: 328-331.

Kirson, E.D. and Y. Yaari. 1996. Synaptic NMDA receptors in developing mouse hippocampal neurones: Functional properties and sensitivity to ifenprodil. J. Physiol. 497: 437-455.

Korte, M., O. Griesbeck, C. Gravel, P. Carroll, V. Staiger, H. Thoenen, and T. Bonhoeffer. 1996. Virus-mediated gene transfer into hippocampal CA1 region restores long-term potentiation in brain-derived neurotrophic factor mutant mice. Proc. Natl. Acad. Sci. 93: 12547-12552.

Korte, M., H. Kang, T. Bonhoeffer, and E. Schuman. 1998. A role for BDNF in the late-phase of hippocampal long-term potentiation. Neuropharmacology 37: 553-559.

Levine, E.S., C.F. Dreyfus, I.B. Black, and M.R. Plummer. 1995. Brain-derived neurotrophic factor rapidly enhances synaptic transmission in hippocampal neurons via postsynaptic tyrosine kinase receptors. Proc. Natl. Acad. Sci. 92: 8074-8077.

1996. Selective role for TrkB neurotrophin receptors

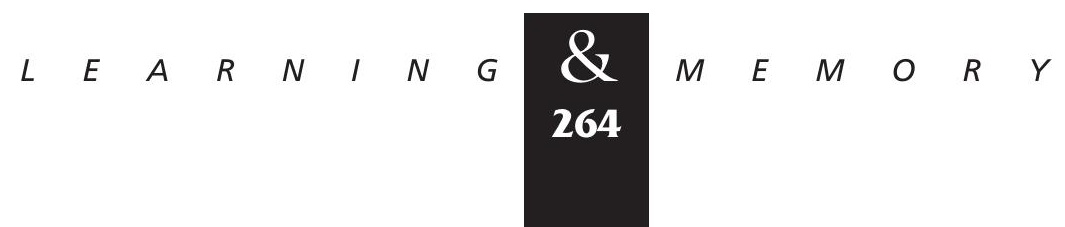


in rapid modulation of hippocampal synaptic transmission. Brain Res. Mol. Brain Res. 38: 300-303.

Levine, E.S., R.A. Crozier, I.B. Black, and M.R. Plummer. 1998. Brain-derived neurotrophic factor modulates hippocampal synaptic transmission by increasing N-methyl-D-aspartic acid receptor activity. Proc. Natl. Acad. Sci. 95: 10235-10239.

Li, J.H., Y.H. Wang, B.B. Wolfe, K.E. Krueger, L. Corsi, G. Stocca, and S. Vicini. 1998. Developmental changes in localization of NMDA receptor subunits in primary cultures of cortical neurons. Eur. J. Neurosci. 10: 1704-1715.

Lin, S.Y., K. Wu, E.S. Levine, H.T. Mount, P.C. Suen, and I.B. Black. 1998. BDNF acutely increases tyrosine phosphorylation of the NMDA receptor subunit $2 \mathrm{~B}$ in cortical and hippocampal postsynaptic densities. Brain Res. Mol. Brain Res. 55: 20-27.

McAllister, A.K., L.C. Katz, and D.C. Lo. 1996. Neurotrophin regulation of cortical dendritic growth requires activity. Neuron 17: 1057-1064.

1999. Neurotrophins and synaptic plasticity. Annu. Rev. Neurosci. 22: 295-318.

Monyer, H., N. Burnashev, D.J. Laurie, B. Sakmann, and P.H. Seeburg. 1994. Developmental and regional expression in the rat brain and functional properties of four NMDA receptors. Neuron 12: 529-540.

Moss, S.J. and T.G. Smart. 1996. Modulation of amino acid-gated ion channels by protein phosphorylation. Int. Rev. Neurobiol. 39: 1-52.

Mowla, S.J., S. Pareek, H.F. Farhadi, K. Petrecca, J.P. Fawcett, N.G. Seidah, S.J. Morris, W.S. Sossin, and R.A. Murphy. 1999. Differential sorting of nerve growth factor and brain-derived neurotrophic factor in hippocampal neurons. J. Neurosci. 19: 2069-2080.

Ogata, N. and H. Tatebayashi. 1991. A simple and multi-purpose "concentration-clamp" method for rapid superfusion. J. Neurosci. Methods 39: 175-183.

Patterson, S.L., T. Abel, T.A. Deuel, K.C. Martin, J.C. Rose, and E.R. Kandel. 1996. Recombinant BDNF rescues deficits in basal synaptic transmission and hippocampal LTP in BDNF knockout mice. Neuron 16: 1137-1145.

Rosenblum, K., Y. Dudai, and G. Richter-Levin. 1996. Long-term potentiation increases tyrosine phosphorylation of the $\mathrm{N}$-methyl-D-aspartate receptor subunit $2 \mathrm{~B}$ in rat dentate gyrus in vivo. Proc. Natl. Acad. Sci. 93: 10457-10460.

Rostas, J.A., V.A. Brent, K. Voss, M.L. Errington, T.V. Bliss, and J.W. Gurd. 1996. Enhanced tyrosine phosphorylation of the $2 \mathrm{~B}$ subunit of the $\mathrm{N}$-methyl-D-aspartate receptor in long-term potentiation. Proc. Natl. Acad. Sci.

93: 10452-10456.

Rutherford, L.C., A. DeWan, H.M. Lauer, and G.G.
Turrigiano. 1997. Brain-derived neurotrophic factor mediates the activity-dependent regulation of inhibition in neocortical cultures. J. Neurosci. 17: 4527-4535.

Rutherford, L.C., S.B. Nelson, and G.G. Turrigiano. 1998. BDNF has opposite effects on the quantal amplitude of pyramidal neuron and interneuron excitatory synapses. Neuron 21: 521-530.

Segal, R.A. and M.E. Greenberg. 1996. Intracellular signaling pathways activated by neurotrophic factors. Annu. Rev. Neurosci. 19: 463-489.

Song, D.K., B. Choe, J.H. Bae, W.K. Park, I.S. Han, W.K. Ho, and Y.E. Earm. 1998. Brain-derived neurotrophic factor rapidly potentiates synaptic transmission through NMDA, but suppresses it through non-NMDA receptors in rat hippocampal neuron. Brain Res. 799: 176-179.

Stocca, G. and S. Vicini. 1998. Increased contribution of NR2A subunit to synaptic NMDA receptors in developing rat cortical neurons. J. Physiol. 507: 13-24.

Strack, S., S. Choi, D.M. Lovinger, and R.J. Colbran. 1997. Translocation of autophosphorylated calcium/ calmodulin-dependent protein kinase II to the postsynaptic density. J. Biol. Chem. 272: 13467-13470.

Suen, P.C., K. Wu, E.S. Levine, H.T. Mount, J.L. Xu, S.Y. Lin, and I.B. Black. 1997. Brain-derived neurotrophic factor rapidly enhances phosphorylation of the postsynaptic $\mathrm{N}$-methyl-D-aspartate receptor subunit 1. Proc. Natl. Acad. Sci. 94: 8191-8195.

Suen, P.C., K. Wu, J.L. Xu, S.Y. Lin, E.S. Levine, and I.B. Black. 1998. NMDA receptor subunits in the postsynaptic density of rat brain: Expression and phosphorylation by endogenous protein kinases. Brain Res. Mol. Brain Res. 59: $215-228$.

Tanaka, T., H. Saito, and N. Matsuki. 1997. Inhibition of GABAA synaptic responses by brain-derived neurotrophic factor BDNF. in rat hippocampus. J. Neurosci. 17: 2959-2966.

Tongiorgi, E., M. Righi, and A. Cattaneo. 1997. Activity-dependent dendritic targeting of BDNF and TrkB MRNAs in hippocampal neurons. J. Neurosci. 17: 9492-9505.

Tovar, K.R. and G.L. Westbrook. 1999. The incorporation of NMDA receptors with a distinct subunit composition at nascent hippocampal synapses in vitro. J. Neurosci. 19: 4180-4188.

Trussell, L.O., L.L. Thio, C.F. Zorumski, and G.D. Fischbach. 1988. Rapid desensitization of glutamate receptors in vertebrate central neurons. Proc. Natl. Acad. Sci. 85: 2834-2838.

Turrigiano, G.G., K.R. Leslie, N.S. Desai, L.C. Rutherford, and S.B. Nelson. 1998. Activity-dependent scaling of quantal amplitude in neocortical neurons. Nature 391: 892-896.

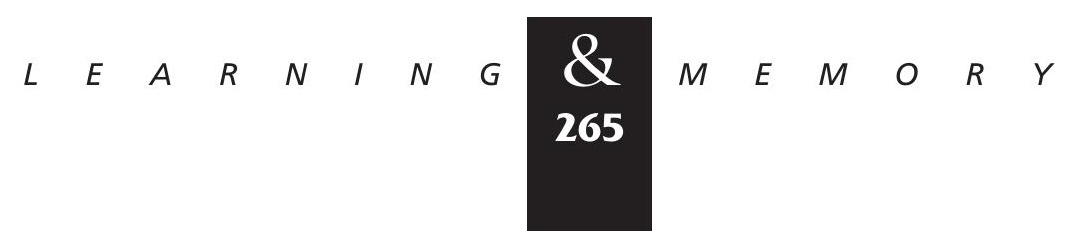




\section{Crozier et al.}

Wang, X.H. and M.M. Poo. 1997. Potentiation of developing synapses by postsynaptic release of neurotrophin-4. Neuron 19: $825-835$.

Williams, K. 1993. Ifenprodil discriminates subtypes of the $\mathrm{N}$-methyl-D-aspartate receptor: Selectivity and mechanisms at recombinant heteromeric receptors. Mol. Pharmacol. 44: 851-859.

Yoshimura, Y. and T. Yamauchi. 1997.

Phosphorylation-dependent reversible association of $\mathrm{Ca} 2+/$ calmodulin-dependent protein kinase II with the postsynaptic densities. J. Biol. Chem.(Tokyo) 272: 26354-26359.

Yoshimura, Y., T. Nomura, and T. Yamauchi. 1996. Purification and characterization of active fragment of $\mathrm{Ca} 2+/$ calmodulin-dependent protein kinase II from the post-synaptic density in the rat forebrain. J. Biochem. 119: $268-273$.

Received May 4, 1999; accepted in revised form June 8, 1999. 


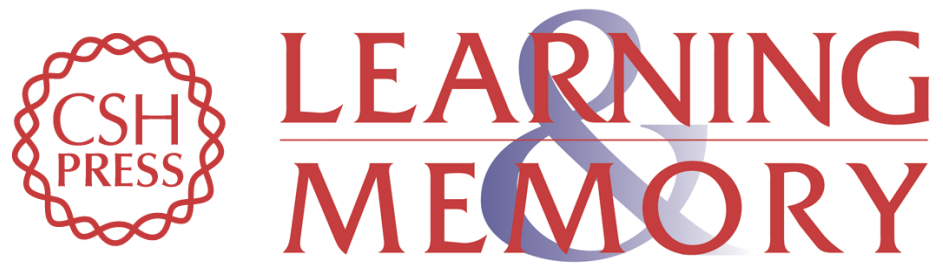

\section{Blockade of NR2B-Containing NMDA Receptors Prevents BDNF Enhancement of Glutamatergic Transmission in Hippocampal Neurons}

Robert A. Crozier, Ira B. Black and Mark R. Plummer

Learn. Mem. 1999, 6:

Access the most recent version at doi:10.1101//m.6.3.257

References This article cites 57 articles, 24 of which can be accessed free at: http://learnmem.cshlp.org/content/6/3/257.full.html\#ref-list-1

License

Email Alerting

Receive free email alerts when new articles cite this article - sign up in the box at the Service top right corner of the article or click here. 